\title{
Working at Pleasure in Young Women's Alcohol \\ Consumption: A Participatory Visual Ethnography
}

Angus Bancroft, Maria Jade Zimpfer, Órla Meadhbh Murray, Martina Karels

Sociological Research Online, 2014, 19, 3, 20.

http://www.socresonline.org.uk/19/3/20.html

\section{Abstract}

The 'student experience' is commodified in UK higher education. It meshes with the commodified intoxication culture around alcohol that has been promoted in the UK by central and local government. Central to this culture is a concept of pleasure as purposeful, unrestrained sociability. It invokes gendered norms of interaction that drinkers both engage with and distance themselves from. Focusing mainly on women, this paper examines that culture critically through the habits, performances, rituals and experiences recounted by student drinkers. For the research, student researcher-participants used smartphones to collect video data about aspects of their intoxication experiences. Pleasure was present but not always dominant in their accounts of leisure focused drinking. They experienced the predominant, neo-liberal concept of pleasure as one mode, which could be engaged alongside others that emphasised a situated, intimate, sociability. Pre-drinking occasions were especially significant as places where bonds could be built up, and the body self-prepared to enter the public nighttime economy. For many, preparation became the main, enjoyable event in contrast to the sometimes fraught and demanding public drinking spaces, where women could find themselves subject to various critical judgements about their femininity. Their activities on these occasions focused on achieving a 'good drunk', a manageable state of group intoxication. We use these findings to comment on the gendering of the night-time economy and the narrow framing of 'pleasure' in public and academic discourses around it.

Keywords: alcohol, pleasure, students, gender, women, visual methods

\section{Introduction}

This paper examines the construction of pleasure in the drinking practices of students between the ages of 18-22 at a British university, using visual ethnographic methods. British Universities sell their 'student experience', in response to a concerted effort by current and past UK and devolved governments to encourage students to think of themselves as consumers of a product, and as products themselves (Sabri, 2013), of which higher fees for English and Welsh students are a part. Pleasure is used to validate and legitimate culturally privileged modes of alcohol consumption and sociability ( $\mathrm{O}^{\prime}$ Malley and Valverde, 2004). Higher education is integrated into the neo-liberal leisure economy, which places a positive value on competence in consumption (Hobbs et al., 2005). The many activities in which people may engage in and identities they may construct around alcohol are reduced to one, that of unbounded, unfettered sociability. Drinking is typically portrayed as ungendered, or unproblematically gendered except in the context of extreme intoxication (Plant 
and Plant, 2006). However the context women drink in is one of unequal leisure, where their drinking may invoke negative judgements, in response to which they create and inhabit fluid leisure spaces (Green and Singleton, 2006).

This paper considers women's drinking practices in terms of a number of challenges for them as they engage with this drinking economy. It theorises their drinking-related activities as, in part, responses to some of the problems the emphasis on unbounded sociability presents for them. It frames these as four practices of pleasure: constructing autonomous spheres; generating anticipation; practicing drinking rituals; and reflecting on events. We examine how they work in terms of friendship groups and boundaries, gendered drinking comportment, the myth of unbounded sociability and the 'good drunk'. We understand them as creating identity in a community of practice, the cohesive, collective ways of producing shared outcomes through action (Lyons and Willott, 2008).

\section{The uses of pleasure in British drinking culture}

The 'pleasure' valued British drinking culture is not necessarily the same as the pleasure in participants' accounts. Pleasure is not a singular positive state of being (Miller, 2008). Luik (1999) identified the problem of obtaining permission for pleasure in a society which divides work from leisure time. The challenge is often presented as achieving pleasure within strict culturally located bounds (Gusfield, 1987). While that dichotomy exists, we found the challenges to be ones of constructing identities, spaces and rituals which can embed pleasure, while maintaining key group and personal boundaries. To adapt Measham (2002), doing drunk is a way of doing gender, and also of having gender done to oneself. It can involve invoking unpleasurable activities such as extreme, forced intoxication in the pursuit of pleasure, and finding pleasure in risk and transgression (Measham and Brain, 2005).

Drinking time is leisure time, but leisure time is not free time (Rojek, 1999). Leisure is governed. The night-time economy is not the 'free space' often advertised, where identities may be created and pleasures experienced without limit or cost (Waitt et al., 2011). Pleasure is a dominant framing of alcohol consumption by both drinkers and the alcohol industry (Bergmark and Kuendig, 2008). It is an aspect of social organisation subject to social control and economic organisation (Bramham, 2011). In the context of alcohol consumption, the rise of the night-time economy in the UK has shaped many drinking spaces and practices (Plant and Plant, 2006). New products and sites of drinking such as alcopops and superpubs resulted from a push by industry and government to regenerate city centres by appealing to young professionals as hedonistic consumers (Chatterton and Hollands, 2003; Hollands and Chatterton, 2003). They have been built around the demands of demonstrative pleasure in alcohol consumption (O'Malley and Valverde, 2004). Drinkers develop rituals and performances that can draw on and encode dominant modes of pleasurable consumption, and also depart from them.

The alcohol and leisure industries put a lot of effort into characterising alcohol as a sociable commodity (European Centre for Monitoring Alcohol Marketing, 2011). The drinker is surrounded by systems that support the concept of pleasure as a state of self-made bliss or contentment, along with a plastic, self- 
making subjectivity (Bunton, 2001; Pitts-Taylor, 2010). In this context, women are positioned as producers of, and adornments to, others' pleasurable experiences and as consumers themselves. Young women are subject to a double standard where they are expected to drink 'like a man' but at risk if they do (Peralta, 2007). Disapproving public discourses around binge drinking emphasise the responsible consumer threatened by an inability to control their own excess (Reith, 2004). At the same time, the image of the sociable party person is promoted as a validated way of being for young people. In contrast to the image of the out of control binge drinker, young people engage in calculated hedonism (Measham and Østergaard, 2009; Szmigin et al., 2008). There is a micro-politics of pleasure and resistance in dance and music, showing how women must position and present themselves in relation to the expectations and actions of others in the scene (Gotfrit, 1991; Gregory, 2009; Skinner, 2008), and we take our cue from this. Women in our study have developed an array of situated, local practices that generate pleasure in context, and guard against various threats to their own identities as pleasure-competent individuals. These variously adapt, avoid and/or go beyond the pleasure-promoting discourses of the night-time economy. We take an embodied approach which emphasises pleasure as a sociable affect that is created in a community of practice through friendship practices and other pleasure-directed activities (Niland et al., 2013). Our methods were designed to reflect this.

\section{Methodology}

We recruited ten sociology students, nine female and one male, as both researchers and participants. All these students were all under 22 years of age, living away from home with other student friends in flats or halls of residences. Six were in first year and three were in third year. Two were British and seven were overseas students.

We conducted a participatory video ethnography. We sought to challenge the divisions and power relationships between researchers and researched. The students took the role of video ethnographers, whereby they were able to guide both the research focus and the interpretation of the video footage they shot, with our research team facilitating and writing up the study. Students were asked to record naturally occurring drinking occasions and their impressions of these events using their own camera-equipped phones. The project team were not present on any of these occasions. The resulting videos took the form of 'confessional' video diaries, interviews, and naturalistic documentary footage. Observations were wide ranging, covering house parties, club scenes, group smoking rituals, pre-drinking sessions, pubs and balls.

We sought to centre otherwise marginalised experiences, in this case, female students' experiences of the night-time economy, private drinking spaces, and the construction of their shared intoxication culture (Mitchell et al., 2012). Using this method we facilitated student researchers to tell their stories and negotiate the complex ethics of filming private spaces and intoxication rituals. These participant-researchers were 'insiders', in that they had a 'significant degree of initial proximity' (Hodkinson, 2005: 134) to those participating in the study, namely, they were their peers, friends and acquaintances. In addition, they engaged in autoethnographic self-reflection and self-observation during their 
fieldwork, using their insider experience but adding a level of critique and analysis (Chang, 2008). Video material allowed us to engage 'all the senses' in viewing and reviewing the data (Pink, 2009).

The presence of someone video recording using a smartphone in many of these settings was not unexpected, and not specifically remarked upon until the student told other participants what they were doing. Pre-drinking groups sometimes arranged for one member of the party to bring a camera and take group photos. This was something that changed as drinking occasions become more settled and routine. In the words of Millie, $3^{\text {rd }}$ year, 'we used to take more photos when we were in first year just because it was exciting but now, not any more. Not really videos at all.' By asking our participant researchers to film, narrate their footage in video diaries, and then discuss both in an interview setting with members of the research team, we provided multiple opportunities for reflexive discussion. The video diary entries and reflection in interviews evoked an autoethnographic aspect to the research, whereby students provided a self-narrative of their experiences alongside accounts and analysis of their friends, acquaintances and others they encountered.

There were two group meetings between students and the research team to review material collected and to identify and discuss emerging themes. Each student's video material was viewed by members of the team to identify topics specific to the material they had collected. They were then interviewed individually. Interviews allowed us to contextualise and clarify events whose substance and meaning in the videos was unclear and to confirm or disconfirm our own readings of them. Students expanded on who was involved and what activities they were engaged in. From this a joint reading of the videos was developed between the interviewer and student.

For example, one student presented us with a sequence of several videos showing: a group of people waiting in a living room; herself talking in a mirror; two people lighting candles on a birthday cake; presenting a birthday cake to the birthday boy; a bedroom ceiling with female voices talking. The sequence could be read as a record of a successful surprise birthday party. After discussing it with her another reading emerged, which was of a group of women meeting to pre-drink before attending a party. They were not looking forward to the event due to the social mix. They developed ways of engaging with, and partly disengaging from, the occasion, including pre-drinking and finding their own space in the bedroom. The student's account showed us the emotional texture of the occasion for them and how it differed from the public face of the party. This privileged access and rapport shows the divergent and contradictory experiences and multiple truths existing within those being researched (Letherby, 2003), who adopt multiple positions as insiders, depending on context and audience alongside identity factors. Along with other research it gives voice to women's perspective on the night-time economy and drinking practices (Haydock, 2009; Holloway et al., 2009; Palmer, 2013; Waitt et al., 2011), which are often portrayed as emulating, or attempting to emulate, men's drinking patterns and rituals (Young et al., 2005). Researchers and those being researched are, 'embodied, emotional, interactive ... striving for meaning in wider historical specific social worlds ...' (Plummer, 2000: 255), and we sought 
to draw on our embedding in the social world and utilise the 'insider' status of ourselves and our participant researchers.

\section{Expanded Reflexivity and Ethics}

Drawing on the ideas of expanded reflexivity (Mauthner and Doucet, 2003) and hidden ethnography (Blackman, 2007), we engaged in a discussion of ethical issues from the planning to the writing up stages. The emotions and relationships that might be relegated to the hidden ethnography and not stated in the official write-up are important to acknowledge, particularly those that might be seen as 'controversial' such as romantic and/or sexual relationships or engaging in drinking or other drug use with participants. These sorts of relationships, alongside general emotional involvement between researchers and participants in research, may be viewed as ethical quandaries, hence why they are often kept hidden. In using a participatory video method with insider participant research, such relationships and practices were inevitable and essential to the research. Our participant-researchers provided, 'a strong position both to empathise and to scrutinise' (Hodkinson, 2005: 144), as they had both personal experience and understanding to draw on and interpret alongside occupying a researcher position that requires them to critically engage with their own and others' experiences. This provided them a good position from which to negotiate ethical concerns, facilitated by the research team.

Whilst our participatory ethnography tried to reduce the imbalance of power between researchers and participants, an unequal dynamic still exists. As Letherby (2003) highlights, those being researched may be unwilling or unable to participate due to the linguistic, time, status, and expected knowledge barriers involved in academic research. Our participatory aspects allowed students to guide the research direction and interpretation though, ultimately, the research team writes up and controls the final output. However, our inductive and participatory interpretation of footage ensured that as far as possible participant-researchers we able to bridge the gap in understanding between the research team and participants.

A key ethical point was the responsibility placed on the participant researchers to not abuse the unfettered access they had to private spaces and conversational topics that a more traditional researcher might not have had. One particular stipulation we had was that students should not film the identities of people engaging in illegal drug use or other illicit activity. Beyond this we had continuing discussions about reputational damage to the participants if they were identifiable in footage, ensured consent as a continuous process, and had an option for participants to opt-out of the research or flag up particular sections of footage that they did not want included. The level and length of engagement did impact the type of material we received. We did not find many embarrassing or unpleasant incidents recorded, although these were part of their drinking occasions. Longer engagement and discussion would perhaps have allowed them greater confidence to address these more negative aspects of their experiences and put them on video or in another form.

In addition, we did not find participants looking much outward from their own settings, for example, to reflect on the strikingly class segregated nature of pubs, 
bars and nightclubs in the city they were based in. This was not something we asked them to do. Another challenge is preserving the fluid identities and performances of participants' lives. We live in a very visual culture that takes visual images to stand for the truth, the master record of events, whereas, as we found, there are multiple readings and meanings of any visual text. Videos can therefore articulate participants' experiences powerfully, but can also stand apart from them, become reified and alienated, the video becoming the permanent record of their lives. A gap opens up between their rich, nuanced, varied experiences and the snapshot that any video must end up being.

\section{Findings}

The paper explores four practices through which pleasure oriented activities were carried out. It considers the effects of these in relation to the myth of unbounded sociability. It argues that many of these activities are about doing the opposite. They maintain boundaries rather than transgress them. They solidify group solidarity rather than anatomise it. We found that alcohol was not by itself 'passage to play' (Gusfield, 1987). The process required a lot of groundwork and identity work, a set of practices, plans, performances, settings that frame agency and sociability. While alcohol is sold as purely a 'pleasure commodity' (Fry, 2011) it is used in a variety of ways and with a range of purposes, as transitional activity, support for intimacy, pathway to excess, marker of group boundaries as well as 'pure pleasure' (Holloway et al., 2009).

\section{Autonomy: Creation of drinking identities and drinking spaces}

The night-time economy appears to have narrowed the public space for variable pleasures into the hedonistic rapid vertical drinking space, while also creating new, supposedly female friendly drinking spaces (Measham, 2004). Drinkers have found ways of generating their own identities, sometimes through partly or wholly withdrawing from the night-time economy (Shaw, 2010) and creating or occupying alternative drinking spaces. There are many drinking spaces outside the night-time world, and many ways of being in the drinking economy that are not purely those of the rapid, socially promiscuous consumer (Roberts et al., 2012). However, women were expected to be consumers of alcohol as part of being young and students:

I never actually played drinking games before university. We occasionally had pre-drinks but not really. We'd have a glass of wine and then go to the pub. We'd get drinks there and maybe go out. So at University, pre-drinks is a much bigger thing and so are drinking games.

Alyssa, interview.

Pleasure was not always foregrounded as the sole or main aim of drinking. It might be for the purpose of getting to know a friendship group, to get drunk, or as an expectation of peers at some points of the night and an option at others.

I think that it's generally quite accepted not to drink at parties when you're out. But I think it's more difficult during pre-drinks. Because when you're out drinking is just one of the things you do. You also have a good time with your friends, and dance, whatever you do really. 
Whereas with pre-drinks, drinking is kind of the point. It's why you're there. It becomes a lot more obvious if you don't drink at pre-drinks. And also, if there are drinking games involved then it might be difficult to play if you're not actively consuming alcohol. You might feel like you are ruining it for your friends if you stay sober. Whereas if you're at a club it's not your fault if you're not drunk.

Summer, video diary.

As highlighted by Summer, each drinking setting had its own interactional character and set of competencies and rituals and was gendered in various ways, which students had more or less control over. A desired characteristic of all the drinking settings they created was that they would be able to manage it in some way, maintaining it as an autonomous zone (Roberts, 2013). This is where predrinking came into play as a way of managing the rest of the night. Alcohol had multiple uses and different types for the purpose. Pre-drinking was one way of women entering into the night-time economy on terms suitable to them (Bancroft, 2012). The high cost of on-trade drinking was given in our interviews as part of the motivation for pre-drinking, but delving deeper it was apparent that pre-drinking had many other desirable attributes (Barton, 2013). The flat pre-party could be intimate, sociable, and less pressured:

That was a little pre-drinks thing we had before we went out and I was just saying how alcohol facilitates maybe behaviour that you wouldn't otherwise be doing. After you've had a few drinks you might get up and dance. That was quite interesting. Then I also ... there was kind of a group that didn't get up and dance. There were people that are very different when they've had a drink. Some people are quite performative and get up and are dancing round and like being the centre of attention. Then other people you know are having a nice chat in the corner and doing that kind of thing

Alyssa, video diary.

\section{Anticipation: Preparing and working on the gendered body}

Pre-drinking sessions had a common structure. In preparation, supplies of alcohol are bought in. Consumption of alcohol was highly structured and directed in these sessions, with one group member often becoming the 'wrangler', who ensured that all members drank at the same high rate. An element of this stage for women was working the body up, preparing the body for public display. Women met up with friends and flatmates at home. Makeup was applied, hair was styled, tans were topped up, photos were taken and uploaded to social networking sites. Many spoke of this process in terms of conformity and fitting in, making themselves comfortable in the pub or club setting. However the practices directed towards fitting in also allowed them to preserve and validate their sense of self within these settings (Foster et al., 2009).

Working on the body could be taken to involve sexualisation and feminisation. These accounts fit with research on new female drinking performances and living the 'post-feminist feminine' (Eldridge and Roberts, 2008). This was a crucial stage in preparing the group, and building group bonds. 
Yeah, we ... five girls who live together. Boyfriends are usually around. They do their own thing. Like go to the pub first. I don't think, getting ready, that process is a boy thing. It's quite a girl thing, taking the whole day to get ready and thinking about what you are going to wear and painting your nails. Like, it's a long process. I don't think it's like that for boys at all so that's a big difference.

Alyssa, interview.

Gender homosociality was important in this group. Alyssa describes interaction in couples, and does not mention male-female friendships. Homosocial groups went to mainstream clubs more often, in some ways a mimicry of the division in the clubs themselves and also as a risk management strategy (Hutton, 2006). In contrast, more mixed groups described by students might attend mainstream clubs less often or not conform to their stipulations in terms of body prep. Accounts by women of illicit drug use at home and in less mainstream or alternative clubs and music scenes did not have these aspects of preparation, reflecting the different practices of femininity involved in each setting. Millie describes this difference:

People who are more aware of problematic gender relations would steer away from some type of clubs because of the image that club has. Everyone is doing rounds but the later it gets some of my male friends will want to buy drinks for the women or will take on buying drinks. But not at the start. So that role comes into play more.

Millie, interview

The cosmetic ritual for women was frequently group-focused. It was confidence building and strengthening of group and friendship bonds in preparation for night out, and also constraining as it required women to conform to a normative ideal of femininity. They were subject to the mutual surveillance and judgement of men and particularly other women.

Fake tan was one common cosmetic practice. The popularity of fake tan could be linked to the rise of the prepared 'beach body' which woman are encouraged to maintain throughout the year (Jordan, 2007). It requires a much longer preparation time than facial cosmetics and is applied over most or all of the body. If a woman wants a smaller surface area covered such as the face and arms she can apply a gradual tan moisturiser, which builds up colour over time. The use of fake tan demonstrates discipline. The male body was not visible or experienced in these accounts as a sexualised or malleable entity in the way that the female body was. In the alternative or underground clubs women and men used makeup in a more performative fashion. This could be interpreted as drawing attention to femininity as literally 'made up' (Negrin, 2000). However the accounts given here indicated that both are performances with similar uses for the women engaging in them.

Makeup in the home and nightclub setting had a dual function as an aspect of a female community of practice, but also of an amplified and sometimes policed femininity. There is something of a tension here between accounts of women 
working on their bodies to help them fit as above, in which doing this gives them a sense of confidence, while at the same time it was experienced as enforced uniformity and structured vulnerability (McRobbie, 2007).

Drinking could also allow them and others to push bodily boundaries:

I usually make fun of my [male] friends if they get handsy, touching your face or saying soppy more emotional things then you can make fun of them if you are less drunk. They might get a little offended but laugh it off. It depends on the closeness. If it's friends of mine I'm not that close with I wouldn't like it. ... It's a lot easier to just be a little bit more uninhibited with your body so you can lie on someone and say 'I'm so tired'. You can act more childishly, and put the focus on yourself more with your body. The music is loud so you need to lean over someone.

Millie, interview.

As Millie describes, this can be funny, unwelcome and unpleasant in the same instance, but is excused by the drinking situation. She can also use it to her advantage and employ the 'childish feminine' trope to be more physically close or intimate than is usually socially acceptable or characteristic.

\section{Rituals and Performances}

The pre-drinking session has established rhythms. When they were preparing for going to a nightclub there was rapid drinking before leaving and shots for ensuring rapid intoxication.

The relationship with shots ... not a good relationship at all. Basically shots are the last resort if you're not feeling drunk enough or you've got a time frame. It's kind of like, we'll do shots. [grimaces]

That's mostly when we do them to be honest. I don't really know anyone who enjoys shots, it's kind of ... our 'go to' when we need to speed up before we leave.

Alyssa, video diary.

A function of pre-drinking was as a time-balancing act. The aim was to arrive at clubs or parties late enough for the atmosphere to be in full swing, but not so late that students would miss it or not get in. The group's drinking pace was timed to ensure peak intoxication on arrival at their destination. The countdown to taxis arriving led to those 'not drunk enough' to take shots or down their drinks in order to 'catch-up' or ensure a level of drunkenness before entering the club. Drinking leaders monitor participant's level of drunkenness to ensure everyone is 'ready' and if, not prescribing them shots.

Alyssa is filming. We see a kitchen table in a flat. There are 5 or 6 women sitting at it, laughing.

Alyssa: Silence! 
(A woman picks up a bottle of flavoured vodka, speaks directly to camera)

Woman: We're about to leave and we're about to be shot! (reading the label) Raspberry Absolut vodka. Woooo! (she dances around the table, arms in the air)

The camera turns to Anna who is sitting down.

Alyssa: It's her birthday! It's her birthday!

The women (chanting): Anna! Anna!

Anna: I've been given some shots.

Alyssa: Are you going to do some shots before you leave?

Anna: I'm going to have to. I'm being forced into it.

Alyssa: It's the countdown. We have to do as many shots as we can.

The women (chanting): Baby shots!

(The women continue their chant and applaud as the first woman takes two shots)

Alyssa, video diary.

The same ritual could also be experienced as forced and needlessly rapid in the accounts of some.

At-home drinking was a practice that was distinct from the rapid consumption focused pre-drinking. These at-home sessions could be defined by their very different rhythm, pace and style of interaction. People would signal their intentions through their choice of alcohol:

And drinking, you notice that people who don't want to get drunk they would opt for drinks like cider or like just a bottle of beer or to beer which they can't get drunk from. But if someone brings a bottle of vodka then you'll think 'oh yes, they do want to get drunk today'.

Although sometimes when somebody isn't getting drunk there is some kind of a pressure from other people to say 'oh come on' because you want them to be on the same level of embarrassment as you are and have fun. There might be some pressure. But if you are strong enough you will know, resist.

Misty, interview.

The rhythm of home dinking changed according to the occasion. In contrast to the rapid pre-drinking session, special occasions were marked with higher quality drinks, such as sparkling wine, for celebrating and preparing at a slower pace: 
We kind of had something when we were celebrating. We normally have vodka because it's cheapest and I don't really like the taste of alcohol that much to be honest. It's the quickest way of having a few drinks. We had Cava on a friend's birthday and on Valentine's Day and it's just a way of creating a sense of occasion, it made it a bit more special. As soon as, we'd start the evening that way. That's the opposite of how we would usually get ready for a night. We usually get ready first and then have drinks, or maybe have one as we go. But that's how we started the evening, we had a bottle of Cava and that got things going. Then we went and got ready. It was nice, it made it more special.

\section{Alyssa, interview.}

The pre-drinking session sometimes became the most enjoyable stage of the evening. It involved lots of preparation, but the main 'event' which was being prepared for, going to a nightclub or party, was often not that much fun. Predrinking for women is best seen as a period in itself with its own interactions and values rather than purely preparation for further drunkenness. During the 'main event', the club or party, drinking would take on a lesser role and consumption might drop.

\section{Gendered Comportment in Public Drinking Places}

Another point of contention in the night-time economy was its explicitly gendered interactional character. Sexual divisions and sexual scripts were accepted by many as part of nightlife (Ronen, 2010). Demands for drunken comportment changed in the setting of the mainstream nightclub compared to pre-drinking. Door staff had to be convinced that women were not too drunk, so drunken comportment had to be moderated. Students reported that men tended to be more closely scrutinised for the effects of extreme alcohol intoxication or illicit drugs. Door staff worked on ensuring that the venue was acceptably balanced between male and female, and that females were sufficiently feminine in appearance. Some mainstream clubs would refuse women entry if they were not wearing makeup or had casual clothes rather than revealing 'party gear' and heels. There was formal and informal surveillance and policing of feminine performance through means such as these.

A club night described by one student drew on the tropes of Mediterranean clubbing tourism. The club made use of female bodies as part of the environment, in the form of both women customers and dancers employed by the club. Students could be more or less critical of the kind of scene being presented, interpreting settings with 'scantily clad dancers' as demeaning, or as pleasurable and holiday-like. There is a heteronormative assumption behind that, which is that men are still the primary consumers to be 'attracted' by the female clientele and atmosphere. This explained some of the attraction of pre-drinking and athome drinking for many women, where feminine performance could genuinely be 'for themselves'.

Mainstream nightclubs had the worst reputation among women students as 'jungle scenes' or 'meat markets'. Sociable interaction was limited in these 
places. They were unable to talk due to the loud music, and needed to look out for other women in their group. Pleasures of behavioural and sexual transgression are promised but also thwarted (Brooks, 2011). There was a double move by club organisers, consisting of the infantilisation of those present combined with the insistent sexual objectification of women, that also reduced men to 'gazers'. So women in the night-time economy can 'become the product' but also view this critically and do work that distances themselves from it. Alternative nightclubs told a very different story and participants often dressed to undermine mainstream masculine and feminine styles, and participated in mixed gender groups.

There was no direct reference in these women's accounts to risk of assault while drinking in public places. This was not probed on, but accounts did show a strong sense of solidarity and being responsible for each other, which referred to a generalised sense of risk.

If you have been pre-drinking though there is quite a group solidarity there. You spend the night checking where your group are and that's quite a good thing, you have a group you are with and it's good to be together. But I anyway have one person I stick with and we go to the loo together and we do everything together for the whole night.

Alyssa.

\section{Friendship groups and boundaries}

Young women form close friendships which have great value in supporting their own pleasure (Griffiths, 1995). The, often single sex, pre-drinking sessions were focused on creating and maintaining coherent friendship groups throughout the night. They could share experiences and look out for each other. Peer motivation was significant in the accounts of women who engaged in pre-drinking:

I think it is quite significant. I mean, not going, and being excluded from the things that happen on our nights out. You really realise it's quite important for the bonding of the group. You know, the next day, if you are not there, you can't chat about the same things they are chatting about and you can't laugh about the same things they are laughing about.

Alyssa, video diary.

Group identities and boundaries were constantly being examined, reexamined and revised.

Women who more often drank in mixed-sex settings or who attended alternative nightclubs and other venues tended to describe their motivations in more individual terms, concerned with establishing their personal identities:

There's a different kind of drunk you encounter. If it's a cocktail bar people tend to take it easier, though not if it's a cocktail bar in [very wealthy area dominated by people in high status professional occupations]. I can't pinpoint why. In metal and punk places people 
seem to be drunker, more crowded, people don't dance their heads off then.

Millie, interview.

Group work could involve maintaining a friendship group in a perceived undesirable setting:

It was a party of friends I made last year and I don't keep in touch with them. I don't enjoy their company and I didn't want to go. That's why before we went for a glass of wine at the pub. To try and settle my nerves, my anxiety about going so I'd feel more comfortable. Once we got the party it was lots of different groups of people. We all sat round in a circle.

Cassie, interview.

Alcohol served the purpose of reducing anxiety and allowed them to make undesired social interactions more pleasant. In contrast to the myths of the night-time economy, it could help them be more confident in not interacting. Cassie goes onto describe in her account of this drinking occasion how they maintained a polite sociability with other groups but as they drunk more they felt able to slip back into socialising in their own friendship groups. Friendship groups formed through pre-drinking could provide support through the night.

\section{Reflection: Repair Work}

At a party, social experience is dependent on intimacy. Not only does intimacy create a comfortable space, but that comfort is necessary for the intoxicating experience to be enjoyable. This is an account of one spin-off group of women who converse in a bedroom during a party:

Woman1: I'm so sorry, like if I made things awkward though between like other people ... it just came up. 'Ugh Cassie! 'Oh, I know Cassie'...

(unidentifiable chatter and laughter. It is explained that Woman 1 was discussing another Cassie)

Cassie: That whole ... what you put in my hair ... it's not even real.

Woman1: It's fluffy.

Cassie: It's not real.

Woman1: It is real.

Woman2: Your hair is lovely.

Woman1: She does have lovely hair, doesn't she?

Woman2: She does.

Cassie: Really? ...

Woman: You have lovely hair. 
(they complement each other on accessories)

Cassie, video diary.

It was in these often unremarked and impromptu intimate sessions that the work of repair, review and reflection took place.

As part of repair work, drinking occasions might be reflected on or reviewed on social media the next day as fun, embarrassing, disgusting, or worrisome. Social media were used in this 'playbour' (Kane, 2005). Memorialisations would be created around using photographs, Tweets, and statuses or messages on Instagram, Facebook or other social networking sites. They mediated an ongoing performance of alcohol use and pleasure that also included telling stories about the night out, reviewing pictures. This meant practices and plans are constantly reviewed in order to strike the perfect balance. Social media brought the performance to a wider friendship group. It provided references for others to 'work towards' what ended up being deemed a 'good night' or a 'good drunk'. This was a practice common across all when accounting for previous drinking and pleasure seeking experiences. They would provide reference for future experiences, where women would constantly revise practices and trying to recreate or relive the best nights through specific drinks, music, locations, conversations, jokes, and anecdotes.

\section{The myth of unbounded sociability}

In spite of the rhetoric of 'free time', the drinking settings were all places where pleasure was uneven, rather than being singular zones of pleasure or danger (Jayne et al., 2010). There was variable intimacy and friendship (Stepney, 2013). As noted by our male respondent, Simon, social mingling did not happen where it was meant to but occurred in places away from the main scene, in queues and groups of smokers. For some individuals, the remoter, more individual intimacy in some settings like nightclubs was more valued than the intensive group intimacy of the pre-drinking session, with its severe obligations. Drink also could give women permission to be unsociable towards strangers and non-group members, in contrast to the image of constant alcohol fuelled open sociability:

Everybody does split off into their groups. The bathroom is a strange one, and the kitchen. Small groups of people just talking. You don't feel obliged to make an effort once you've had a drink or maybe several drinks (laughs).

Cassie, interview

Despite the reputation of parties as occasions for social mixing, friendships tended to be formed in time outs from the main scene:

There are little private spin off groups that form when for example going out for a cigarette when the interaction and topic of conversation quickly changes to something more intimate.

Cassie, interview. 
In private parties students often found a jumble of legal, unlicensed and illicit drugs, an easy mingling of people, or a splitting-off into smaller shared interest groups. Women created private spaces at parties and in nightclub toilets. These have qualities akin to the often invisible bedroom cultures of younger women, where they create semi-private, manageable zones (Lincoln, 2004). These aspects of their drinking practices helped them to manage the transition between the home and the night-time economy.

\section{Achieving the 'good drunk'}

Identity and comportment were encapsulated in the phrase 'a good drunk'. It was a state of being both personable and sociable. It means everyone in the group is at the same level of drunkenness. Nobody is sober and nobody is out of control. It also means that the individual feels themself to be talkative and comfortable.

Rituals were oriented to ensuring a good drunk for the group, showing it as a group monitored and measured state:

It's basically looking at people's behaviour. There's times I see people who are quite loud who've only had a couple of drinks. It's about monitoring people's behaviour. So if someone is being loud... it's mostly the person who seems sober. If you see someone who looks like they haven't had a drink or haven't had a go in the drinking game you are playing or whatever you pick on them to make sure they have one.

Alyssa, interview.

Drinking games were used to encourage consumption and ensure that participants were at a similar level of intoxication:

And then to be honest because I was recording I wasn't really paying attention to the rules. Then I ended up drinking the most because I didn't know what was happening and when. But yeah so we all had fun with it. I guess it was just very fast way of getting drunk.

Misty, interview.

Group members could monitor one another's intoxication. In the predrinking stage they would cajole each other into consuming more alcohol. In the nightclub this would be done with the opposite aim. Women would look out for friends who were 'too drunk' and who might catch the eye of security staff and be ejected from the premises, or who might be unable to look after themselves. This was part of maintaining 'the night':

To get, maybe not pissed, but to a certain level of comfortable drunkenness is definitely a goal, also to keep the night going. If you got throughout the night then stop then it's over. And you leave and go back to your flat, your night out has ended.

Millie, video diary. 
Good drinking was partly about managing the effect on one's sense of balance and proprioception, avoiding heels wobbling on cobblestones under the scrutiny of door staff. A bad drunk had features of losing self-control, being separated from the group in public environments, and being at risk.

They put me off getting really drunk. I don't enjoy being really drunk. Bad things happen. You lost things, maybe had an argument with someone. A bad experience in that way might put you off being drunk.

Alyssa.

The meaning of a good drunk also changed over their university career. They changed depending on the kind of pre-University drinking experiences they had and the orientation to pleasurable drinking they had developed.

First year was a lot of house parties and we would also go to clubs more I think although we were in one of those first years who were partying in clubs every week or a few nights a week. But then it seriously declined.

Misty, interview.

Freshers' week and first year were times for binge drinking. For these students there was a rapid maturing out, and a view that extreme drinking practices were time and place bounded. When these happened after first year they were recounted as reminiscent of past 'mad times' and were rare.

\section{Conclusion}

In this paper we have portrayed a pleasure that contrasts with the supposed hedonism of the night-time economy, even when it crosses paths with it and makes use of it.

The nature of the data collected has shaped our conclusions. These are young largely unattached students at university and they appear to enjoy a 'free time' approach to drinking. They were part of the traditional student market, relatively unfettered, away from home, able to consume and interact with pleasure and abandon in these settings. A lot of the talk was of the perspective of alcohol as freeing, creating a space where one could perform, demonstrate one's own identity. Even so, we could see how women had to deal with the dual role of 'feminine' and 'pleasure-subject'. Pleasure was not unconstrained agency. Women would build up a variety of practices and settings to create space for agency and identity, and to do that sometimes had to work against the norms of the night-time economy. The ways in which they did engage in this sort of alcohol consumption was only a part of their drinking experience and not necessarily the most pleasurable.

The research explodes some myths of the pleasure economy: that everyone wants to mix; that drinking alcohol breaks down group barriers; that all present are interested in hedonism. Many of the practices our women engaged in were about precisely not breaking down some of those barriers. Accounts recognised the different pressures exerted on women in the night-time economy and its reduction of drinking practices to those of a positive, extrovert sociability. Their 
practices were an adaption to this. Students certainly could be very positive and extrovert, and find delight and fun in many different drinking settings. However these experiences were always situated in their own carefully calibrated drinking practices. The culture of these manageable, private zones can be extended and embedded by social media. A lot of work was spent on prosumption (Ritzer and Jurgenson, 2010), with social media messages to plan pre-drinking, arranging to bring drink, sharing music and nightclub fliers, and Facebook updates to dissect the night's events in the following days (Fjær, 2012).

McRobbie $(2009,2007)$ argues that there has been a closing off of political space for autonomous feminism through the colonisation of social space by various cultural and sexual freedoms for women. The 'Girl' becomes a fun loving subject. We argue that many of the practices we recount involved grappling with the problems this subjectivity represents. They could be read as necessary preparation and personal psychological management of these contradictions. However they indicate more active and critical response is possible. Certainly some respondents were aware and explicitly resisted the 'masquerade' in a way which could be seen as a 'resistant promenade' (Blackman, 1997). In either case the communities of practice they formed around alcohol allowed them both to be, and to be more than, the pleasure-promoting subject.

\section{Acknowledgements}

We would like to thank the anonymous referees for their very constructive and thoughtful comments. Our special thanks to our student participants, without whom this study would have never happened.

\section{References}

BANCROFT, ANGUS (2012) 'Drinking with and Without Fun: Female Students' Accounts of Pre-Drinking and Club-Drinking', Sociological Research Online 17(4): 7 <http://www.socresonline.org.uk/17/4/7.html> $10.5153 /$ sro. 2785 .

BARTON, ADRIAN (2013) “'I Don”t Really like the Pub": Reflections on Young People and Pre-Loading Alcohol'. Presented at the Under Control? Alcohol and Drug Regulation Past and Present Conference.

Bergmark, Karin Helmersson and Hervé Kuendig (2008) 'Pleasures of Drinking: A Cross-Cultural Perspective', Journal of Ethnicity in Substance Abuse 7(2): 131-53.

Blackman, Shane J. (1997) 'The School: "Poxy Cupid!” - An Ethnographic and Feminist Account of a Resistant Female Youth Culture: The New Wave Girls', pp. 208-28 in Skelton, T. and Valentine, G. (eds), Cool Places: Geographies of Youth Cultures. London: Routledge.

Blackman, SHANE J. (2007) “"Hidden Ethnography”: Crossing Emotional Borders in Qualitative Accounts of Young People's Lives', Sociology 41(4): 699-716.

Bramham, Peter (2011) 'Choosing Leisure: Social Theory, Class and Generations', pp. 11-31 in Bramham, P. and Wagg, S. (eds), The New Politics of Leisure and Pleasure. Houndmills: Palgrave MacMillan.

BrooKs, Oona (2011) “'Guys! Stop Doing It!”: Young Women's Adoption and Rejection of Safety Advice When Socializing in Bars, Pubs and Clubs', British Journal of Criminology 51(4): 635-51. 
Bunton, RoBin (2001) 'Knowledge, Embodiment and Neo-Liberal Drug Policy', Contemporary Drug Problems 28: 221-43.

Chang, HeEwon (2008) Autoethnography as Method. Walnut Creek, CA: Left Coast Press.

Chatterton, Paul and Robert Hollands (2003) Urban Nightscapes: Youth Cultures, Pleasure Spaces and Corporate Power. London: Routledge.

ELDRIDGE, AdAM AND MARION RoBERTS (2008) 'Hen Parties: Bonding or Brawling?', Drugs: Education, Prevention, and Policy 15(3): 323-8.

European Centre for Monitoring Alcohol Marketing (2011) The Seven Key Messages of the Alcohol Industry. Utrecht: EUCAM.

FJÆR, EIVIND GRIP (2012) 'The Day after Drinking: Interaction during Hangovers among Young Norwegian Adults', Journal of Youth Studies 15(8): 9951010.

Foster, John et Al. (2009) Why Do People Drink at Home? An Exploration of the Perceptions of Adult Home Consumption Practices. London: Alcohol Education and Research Council.

FRY, MARIE-LoUISE (2011) 'Seeking the Pleasure Zone: Understanding Young Adult's Intoxication Culture', Australasian Marketing Journal 19(1): 65-70.

GoTfRIT, LESLIE (1991) 'Women Dancing Back: Disruption and the Politics of Pleasure', pp. 174-95 in Giroux, H.A. (ed.), Postmodernism, Feminism, and Cultural Politics: Redrawing Educational Boundaries. Albany, NY: State University of New York Press.

GreEn, EiLEEn AND CaRrie Singleton (2006) 'Risky Bodies at Leisure: Young Women Negotiating Space and Place', Sociology 40(5): 853-71.

Gregory, Julie (2009) 'Too Young to Drink, Too Old to Dance: The Influences of Age and Gender on (non) Rave Participation', Dancecult: Journal of Electronic Dance Music Culture 1(1): 65-80.

GRIFFITHS, ViviEnNe (1995) Adolescent Girls and Their Friends: A Feminist Ethnography. Aldershot: Avebury.

Gusfield, JosePh R (1987) 'Passage to Play: Rituals of Drinking Time in American Society', pp. 73-90 in Douglas, M. (ed.), Constructive Drinking: Perspectives on Drink from Anthropology. Cambridge: Cambridge University Press.

Haydock, W. (2009) Gender, Class and 'Binge' Drinking: An Ethnography of Drinkers in Bournemouth's Night-Time Economy. (PhD).

HoBBS, DicK ET AL. (2005) 'Violent Hypocrisy Governance and the Night-Time Economy', European Journal of Criminology 2(2): 161-83.

Hodkinson, PAUL (2005) "Insider Research" in the Study of Youth Cultures', Journal of Youth Studies 8(2): 131-49.

Hollands, Robert ANd PAul ChatTERTon (2003) 'Producing Nightlife in the New Urban Entertainment Economy: Corporatization, Branding and Market Segmentation', International Journal of Urban and Regional Research 27(2): 361-85.

HollowaY, S. L. ET AL. (2009) 'Masculinities, Femininities and the Geographies of Public and Private Drinking Landscapes', Geoforum 40(5): 821-31.

Hutton, Fiona (2006) Risky Pleasures?: Club Cultures and Feminine Identities. Avebury: Ashgate Publishing Limited.

JAYNE, MARK ET AL. (2010) 'Emotional, Embodied and Affective Geographies of Alcohol, Drinking and Drunkenness', Transactions of the Institute of British Geographers 35(4): 540-54. 
JoRdAN, Fiona (2007) 'Life's a Beach and Then We Diet: Discourses of Tourism and the "Beach Body" in UK Women's Lifestyle Magazines', pp. 92-106 in Pritchard, A. et al. (eds), Tourism and Gender: Embodiment, Sensuality and Experience. Wallingford: CABI.

Kane, PAT (2005) The Play Ethic: A Manifesto for a Different Way of Living. London: Macmillan.

Letherby, GAYLE (2003) Feminist Research in Theory and Practice. Buckingham: Open Univeristy Press.

Lincoln, Sian (2004) 'Teenage Girls “Bedroom Culture”: Codes versus Zones', pp. 94-106 in Bennett, A. and Kahn-Harris, K. (eds), After Subculture: Critical Studies in Contemporary Youth Culture. New York: Palgrave MacMillan. URL (consulted July 2013): http://mediaucn.co.uk/Seminar\%20Readings/Soc\%203016/Sian's\%20article\%20on \%20bedrooms+teens.pdf

LuIK, JoHn (1999) 'Wardens, Abbots, and Modest Hedonists: The Problem of Permission for Pleasure in a Democratic Society', pp. 25-36 in Peele, S. and Grant, M. (eds), Alcohol and Pleasure: A Health Perspective. Philadelphia: Brunner/Mazel.

Lyons, Antonia C. And SARa A. Willott (2008) 'Alcohol Consumption, Gender Identities and Women's Changing Social Positions', Sex Roles 59(9-10): 694-712.

Mauthner, Natasha S. And Andrea Doucet (2003) 'Reflexive Accounts and Accounts of Reflexivity in Qualitative Data Analysis', Sociology 37(3): 413-31.

McRobbie, Angela (2007) 'Top Girls?', Cultural Studies 21(4-5): 718-37.

McRobbie, Angela (2009) The Aftermath of Feminism: Gender, Culture and Social Change. London: Sage.

Measham, Fiona (2002) “'Doing Gender" - "Doing Drugs”: Conceptualizing the Gendering of Drugs Cultures', Contemporary Drug Problems 29: 335-73.

Measham, Fiona (2004) 'Play Space: Historical and Socio-Cultural Reflections on Drugs, Licensed Leisure Locations, Commercialisation and Control', International Journal of Drug Policy 15(5-6): 337-45.

Measham, Fiona and Kevin Brain (2005) “"Binge” Drinking, British Alcohol Policy and the New Culture of Intoxication', Crime, Media, Culture 1(3): 262-83.

Measham, Fiona And Jeanette ØstergaArd (2009) 'The Public Face of Binge Drinking: British and Danish Young Women, Recent Trends in Alcohol Consumption and the European Binge Drinking Debate', Probation Journal 56(4): $415-434$.

Miller, Alistair (2008) 'A Critique of Positive Psychology-or "The New Science of Happiness"', Journal of Philosophy of Education 42(3-4): 591-608.

Mitchell, Claudia eT AL. (2012) 'Introduction', pp. 1-18 in Milne, E. et al. (eds), Handbook of Participatory Video. Lanham: AltaMira Press.

Negrin, Llewellyn (2000) 'Cosmetics and the Female Body: A Critical Appraisal of Poststructuralist Theories of Masquerade', European Journal of Cultural Studies 3(1): 83-101.

Niland, PAtricia ET AL. (2013) “"Everyone Can Loosen up and Get a Bit of a Buzz On": Young Adults, Alcohol and Friendship Practices', International Journal of Drug Policy 24(6): 530-7. 
O’Malley, Pat and Mariana Valverde (2004) 'Pleasure, Freedom and Drugs: The Uses of "Pleasure" in Liberal Governance of Drug and Alcohol Consumption', Sociology 38(1): 25-42.

Palmer, Catherine (2013) 'Drinking like a Guy? Women and Sport-Related Drinking', Journal of Gender Studies early online.

Peralta, Robert L (2007) 'College Alcohol Use and the Embodiment of Hegemonic Masculinity Among European American Men', Sex Roles 56(11-12): 741-56.

PInk, SARAH (2009) Doing Sensory Ethnography. SAGE Publications Ltd.

PITTS-TAYLOR, ViCTORIA (2010) 'The Plastic Brain: Neoliberalism and the Neuronal Self', Health: 14(6): $635-652$.

Plant, Martin and Moira Plant (2006) Binge Britain: Alcohol and the National Response. Oxford: Oxford University Press.

Plummer, Ken (2000) Documents of Life 2: An Invitation to A Critical Humanism. London: SAGE.

REITH, GERDA (2004) 'Consumption and Its Discontents: Addiction, Identity and the Problems of Freedom', British Journal of Sociology 55(2): 283-300.

Ritzer, George And NATHAN JuRgenson (2010) 'Production, Consumption, Prosumption: The Nature of Capitalism in the Age of the Digital "Prosumer"', Journal of Consumer Culture 10(1): 13-36.

RoBerts, MARION ET AL. (2012) Local Variations in Youth Drinking Cultures. York: Joseph Rowntree Foundation. URL (consulted April 2014): http://www.jrf.org.uk/publications/local-variations-youth-drinkingcultures

Roberts, MARIOn (2013) “'A Big Night Out”: Young People’s Drinking, Social Practice and Spatial Experience in the "Liminoid" Zones of English NightTime Cities', Urban Studies: 0042098013504005.

Rojek, Chris (1999) 'Abnormal Leisure: Invasive, Mephitic and Wild Forms', Loisir et Société / Society and Leisure 22(1): 21-37.

Ronen, Shelly (2010) 'Grinding On the Dance Floor: Gendered Scripts and Sexualized Dancing at College Parties', Gender \& Society 24(3): 355-77.

SABRI, DunA (2013) 'Student Evaluations of Teaching as "Fact-Totems": The Case of the UK National Student Survey', Sociological Research Online 18(4): 15.

Shaw, Robert (2010) 'Neoliberal Subjectivities and the Development of the Night-Time Economy in British Cities', Geography Compass 4(7): 893-903.

Skinner, Jonathan (2008) 'Women Dancing Back-and Forth: Resistance and Self-Regulation in Belfast Salsa', Dance Research Journal 40(1): 65-77.

STEPNEY, MELISSA (2013) 'British Women's Experiences of Drinking Alcohol: Dynamics of Emotional Proximity and Distance', Emotion, Space and Society Early online.

SzMIGIN, ISABELLE ET AL. (2008) 'Re-Framing "Binge Drinking” as Calculated Hedonism: Empirical Evidence from the UK', International Journal of Drug Policy 19(5): 359-66.

WAITT, GORDON ET AL. (2011) "The Guys in There Just Expect to Be Laid": Embodied and Gendered Socio-Spatial Practices of a "Night Out" in Wollongong, Australia', Gender, Place \& Culture: A Journal of Feminist Geography 18(2): 255.

YounG, Amy M. ET AL. (2005) 'Drinking Like a Guy: Frequent Binge Drinking Among Undergraduate Women', Substance Use \& Misuse 40(2): 241-67. 
